\title{
PENGUJIAN FORMULASI KERING Metarhizium anisopliae ISOLAT UGM DAN TEGINENENG SERTA Beauveria bassiana ISOLAT TEGINENENG UNTUK MEMATIKAN Helopeltis spp. DI LABORATORIUM DAN DI LAPANGAN
}

\author{
Nazomi Irawan, Purnomo, Indriyati \& Lestari Wibowo \\ Jurusan Agroteknologi, Fakultas Pertanian Universitas Lampung \\ Jl. Prof. Dr. Soemantri Brodjonegoro no. 1 Bandar Lampung 35145 \\ Email : nazomi28@gmail.com
}

\begin{abstract}
ABSTRAK
Pemanfaatan musuh alami sebagai agensia pengendali hayati mempunyai beberapa keuntungan seperti mencegah resistensi hama, biaya relatif murah,dan aman bagi lingkungan. Salah satu musuh alami yang dapat digunakan untuk mengendalikan hama adalah jamur entomopatogen. Jamur entomopatogen dapat dikemas dalam bentuk formulasi kering. Keuntungan dari formulasi kering ini diantaranya dapat disimpan dalam jangka waktu yang lama, praktis, dan mudah diaplikasikan. Penelitian ini bertujuan mengetahui pengaruh lama simpan formulasi kering $M$. anisopliae isolat UGM dan isolat Tegineneng serta $B$. bassiana isolat Tegineneng dalam mematikan Helopeltis spp. di laboratorium dan mengetahui pengaruh formulasi kering dari 3 jenis jamur patogen tersebut dalam mematikan Helopeltis spp. di lapangan. Penelitian terdiri dari percobaan di laboratorium dan di lapangan. Percobaan di laboratorium dirancang menggunakan Rancangan Acak Kelompok (RAK) dan dianalisis dengan menggunakan uji Duncan taraf nyata 5\%. Percobaan di lapangan dirancang menggunakan Rancangan Acak Kelompok (RAK) dan dianalisis ragam serta dilanjutkan dengan uji BNT dengan taraf nyata 5\%. Hasil penelitian di laboratorium menunjukkan bahwa kemampuan formulasi kering jamur $M$. anisopliae isolat UGM, $M$. anisopliae isolat Tegineneng serta $B$. bassiana isolat Tegineneng dalam menginfeksi Helopeltis spp. semakin rendah dengan semakin lama penyimpanan formulasi kering tersebut. Hasil penelitian di lapangan menunjukkan bahwa kemampuan formulasi kering jamur M. anisopliae isolat UGM, M. anisopliae isolat Tegineneng serta B. bassiana isolat Tegineneng yang tidak mengalami masa simpan sangat efektif dalam menginfeksi Helopeltis spp. yakni sebesar 83,3\% dan 76,6\%. Selain itu aplikasi formulasi kering ketiga jamur entomopatogen di lapangan dapat mengurangi kerusakan pada buah kakao dengan mengurangi jumlah tusukan perbuah.
\end{abstract}

Kata kunci : Beauveria bassiana, formulasi kering, Helopeltis spp., masa simpan, Metarhizium anisopliae, mortalitas.

\section{PENDAHULUAN}

Kakao (Theobroma cacao L.) merupakan salah satu komoditas perkebunan yang mempunyai peran penting dalam perekonomian Indonesia. Tahun 2010 Indonesia merupakan pengekspor biji kakao terbesar ketiga dunia dengan produksi biji kering 550.000 ton setelah Negara Pantai Gading (1.242.000 ton) dan Ghana dengan produksi 662.000 ton (ICCO, 2011 dalam Balittri, 2012). Namun dalam budidaya kakao terdapat berbagai kendala. Menurut Suparno (2000), salah satu kendala yang dihadapi dalam budidaya kakao adalah serangan hama. Salah satu hama penting pada tanaman kakao adalah penghisap buah kakao (Helopeltis spp.).
Hama penghisap buah kakao (Helopeltis spp.) dapat menimbulkan kerusakan dengan cara menusuk dan menghisap cairan buah maupun tunas muda. Serangan pada buah kakao muda menyebabkan matinya buah, menyerang tunas muda atau pucuk, sedangkan serangan pada buah berumur sedang menyebabkan terbentuknya buah abnormal, akibatnya hasil dan mutu kakao menurun karena biji yang dihasilkan berukuran kecil. Serangan berat dan berulang pada buah dan pucuk dapat menyebabkan penurunan produksi kakao sekitar 36-75\% (Sulistyowati \& Sardjono, 1988 dalam Amini, 2011). Pada umumnya pengendalian secara kimia menjadi pilihan utama para petani kakao, namun menurut Susilo (2007) penggunaan insektisida kimia yang 
berkepanjangan dapat menimbulkan peledakan hama serta berdampak negatif terhadap lingkungan.

Metode pengendalian hama yang berwawasan lingkungan, diperlukan kajian tentang peranan musuh alami sebagai agensia untuk mengendalikan hama. Salah satu agensia hayati yang potensial sebagai sarana pengendalian hama adalah jamur entomopatogen (Indriyati, 2009). Penggunaan musuh alami seperti jamur entomopatogen adalah pengendalian yang efektif karena pengendalian ini aman dan ramah lingkungan serta keuntungan dari jamur entomopatogen yang dibuat dalam bentuk formulasi kering ini diantaranya adalah dapat disimpan dalam jangka waktu yang lama, praktis, dan mudah diaplikasikan (Mulya et al., 2002).

Menurut hasil penelitian Dwipayana (2013) di laboratorium menunjukkan bahwa konsentrasi $25 \mathrm{~g} \mathrm{l}^{-1}$ dari jamur B. bassiana isolat Tegineneng formulasi kering dapat menyebabkan kematian Helopeltis spp. sebesar $63,33 \%$ pada 8 hari setelah aplikasi. Hasil penelitan Erdiyanto (2013) di laboratorium pada konsentrasi $20 \mathrm{~g} \mathrm{l}^{-1}$ formulasi kering Metarhizium anisopliae isolat UGM mortalitas Helopeltis spp. mencapai $90,16 \%$. Adapun menurut hasil penelitian Saputra (2013) di laboratorium pada konsentrasi 20 $\mathrm{g} \mathrm{l}^{-1}$ formulasi kering jamur Metarhizium anisopliae isolat Tegineneng mortalitas Helopeltis spp. sebesar $72,26 \%$.

Menurut Prayogo \& Tengkano (2002) penyimpanan yang terlalu lama dari jamur entomopatogen akan menyebabkan menurunnya kemampuan jamur untuk mematikan serangga. Berdasarkan uraian di atas maka perlu adanya penelitian lebih lanjut tentang pengaruh lama simpan formulasi kering. Dalam penelitian ini dilihat pengaruh lama simpan dari jamur B. bassiana isolat Tegineneng serta $M$. anisopliae isolat Tegineneng dan UGM dalam mematikan hama Helopeltis spp.

Penelitian ini bertujuan untuk mengetahui pengaruh lama simpan formulasi kering $M$. anisopliae isolat UGM dan isolat Tegineneng serta $B$. bassiana isolat Tegineneng dalam mematikan Helopeltis spp. di laboratorium dan untuk mengetahui pengaruh aplikasi formulasi kering dari 3 jenis jamur patogen tersebut dalam mematikan Helopeltis spp. di lapangan.

\section{BAHAN DAN METODE}

Penelitan ini dilaksanakan di laboratorium dan di lapangan. Percobaan di laboratorium dilakukan di Laboratorium Hama Tanaman, Fakultas Pertanian, Universitas Lampung sejak bulan April sampai dengan bulan Desember 2013. Penelitian di lapangan dilakukan di kebun kakao yang ada di Jalan Purnawirawan IV, Kelurahan Gunung Terang, Kecamatan Tanjung Karang Barat sejak bulan Januari sampai dengan bulan Febuari 2014.

Penelitian terdiri dari percobaan di laboratorium dan di lapangan. Percobaan di laboratorium terdiri atas 3 set percobaan yaitu percobaan set pertama pengujian pengaruh lama simpan formulasi kering jamur $M$. anisopliae isolat UGM, set kedua isolat Tegineneng serta set ketiga $B$. bassiana isolat Tegineneng terhadap mortalitas hama Helopeltis spp. Pada percobaan di laboratorium, percobaan disusun dalam Rancangan Acak Kelompok (RAK), Sebagai perlakuan adalah aplikasi formulasi kering jamur entomopatogen yang telah mengalami penyimpanan 1 sampai dengan 12 bulan. Setiap percobaan menggunakan ulangan sebanyak tiga kali. Setiap satu satuan percobaan terdiri dari 20 ekor imago Helopeltis spp. Data mortalitas Helopeltis spp. Untuk percobaan di laboratorium, dianalisis dengan menggunakan uji Duncan taraf nyata 5\%.

Percobaan kedua dilakukan di lapangan, yaitu aplikasi jamur $M$. anisopliae isolat Tegineneng dan UGM serta B. bassiana isolat Tegineneng terbaru, yang dibuat pada tanggal 3 November 2013. Formulasi kering yang diuji di lapangan disusun dengan menggunakan Rancangan Acak Kelompok (RAK), dan dianalisis ragam serta dilanjutkan dengan uji BNT dengan taraf nyata 5\%, dengan 4 perlakuan dan 6 ulangan. Setiap satuan percobaan terdiri dari satu buah kakao yang mulus tanpa gejala kerusakan dan berumur 1,5-2,5 bulan. Pengujian di lapangan dilaksanakan pada tanggal 15 Januari 2014 di kebun kakao. Pengamatan di lapangan dilakukan pada pagi hari dengan cara melihat banyaknya tusukan buah kakao yang ditimbulkan oleh hama Helopeltis spp. serta menghitung populasi Helopeltis spp. mati di buah kakao pasca aplikasi jamur entomopatogen tersebut.

Pembiakan serangga menggunakan inang alternatif mentimun. Sebelum pembiakan terlebih dahulu dilakukan pencarian indukan Helopeltis spp. di lapangan. Indukan imago dan nimfa dipisahkan dan dimasukkan ke dalam stoples plastik berdiameter $16 \mathrm{~cm}$ dengan tinggi $17 \mathrm{~cm}$ yang sudah ada pakan mentimun di dalamnya dan ditutup menggunakan kain sippon. Setiap stoples diisi 20 ekor Helopeltis spp. dan \pm 2 buah mentimun. Setelah imago bertelur, maka mentimun yang digunakan sebagai media bertelur dipisahkan dan ditempatkan pada stoples yang baru lalu ditutup dan diberi label tanggal. Setelah telur menetas, maka nimfa dipindahkan kedalam stoples yang baru dan diberi mentimun yang masih segar. Begitu seterusnya sampai diperoleh jumlah Helopeltis spp. yang diperlukan. 
Sabouraud Dextrose Agar merupakan media yang mengandung pepton di dalamnya Sabouraud Dextrose Agar merupakan media yang mengandung pepton di dalamnya. Satu liter media ini dikomposisikan dari $40 \mathrm{~g}$ Dextrose, $15 \mathrm{~g}$ agar, $5 \mathrm{~g}$ pepton, $5 \mathrm{~g}$ kasein dan 1 liter air destilata. Semuanya dimasukkan kedalam tabung Erlenmeyer kemudian ditutup menggunakan alumunium foil, dikencangkan dengan karet gelang dan dibungkus plastik tahan panas. Selanjutnya di autoklaf selama \pm 2 jam. Setelah itu Media Sabouraud Dextrose Agar (SDA) diangkat dan didiamkan sebentar supaya sedikit lebih dingin. Kemudian dituangkan kemasingmasing petridish dalam ruangan steril (Laminar Air Flow).

Beras dicuci sampai bersih, kemudian disiram dengan air mendidih. Beras dikukus hingga setengah matang, kemudian diangkat dan dikeringanginkan. Sekitar $150 \mathrm{~g}$ beras setengah matang dimasukkan dalam kantong plastik. Beras dipadatkan dan diposisikan pada bagian bawah plastik. Bagian atas plastik yang tidak terisi dirapikan, digulung, dan diikat dengan karet gelang. Beras disterilkan dengan autoklaf pada suhu $120^{\circ} \mathrm{C}$, tekanan $1 \mathrm{~atm}$, selama 15 menit. Beras diangkat dan dikeringanginkan, kemudian diinokulasi dengan isolat $M$. anisopliae, B. bassiana, selanjutnya diinkubasi selama 2 minggu.

Pembuatan formulasi kering untuk menguji lama penyimpanan telah dibuat pada bulan November 2012 sedangkan untuk pengujian formulasi kering di lapangan di buat baru pada tanggal 3 November 2013 dengan menggunakan metode pembuatan yang sama. Dalam penelitian ini, pembuatan formulasi kering $M$. anisopliae dan B. bassiana mengacu pada Purnomo et al. (2012). Pembuatan formulasi kering dimulai dengan mengeringkan jamur $M$. anisopliae dan B. bassiana yang tumbuh pada media beras. Pengeringan dilakukan dengan pengeringan dingin. Pengeringan dingin dilakukan di dalam lemari es pada suhu $5^{\circ} \mathrm{C}$ selama 12 hari. Setelah kering jamur $M$. anisopliae dan $B$. bassiana dihaluskan dengan cara diblender lalu diayak sehingga menjadi tepung biomassa spora $M$. anisopliae dan $B$. bassiana. Bahan pembawa seperti tepung jagung, kaolin, dan zeolit juga disterilkan dengan oven pada suhu $80^{\circ} \mathrm{C}$ selama 2 jam. Setelah itu tepung biomassa spora $M$. anisopliae dan B. bassiana dicampur dengan bahan pembawa (Tabel 1).

Aplikasi formulasi kering berbahan aktif jamur M. anisopliae konsentrasi $20 \%$ dan B. bassiana konsentrasi $25 \%$ dilakukan dengan cara melarutkan formulasi kering dengan air. Setelah itu ditambahkan bahan perata perekat (indostick) sebanyak $1 \mathrm{ml} \mathrm{l}^{-1}$. Pelaksanaan pengujian formulasi kering dilakukan dengan memasukkan 20 ekor imago Helopeltis spp. per satu satuan percobaan ke dalam botol air mineral yang dipotong bagian atas dan bagian bawahnya. Setelah itu pada bagian bawah botol tersebut ditutup dengan kain strimin dan diikat dengan karet gelang. Formulasi kering yang sudah dicampur dengan air dan bahan perekat diaplikasikan menggunakan handsprayer. Selanjutnya serangga yang sudah diaplikasikan dimasukkan kembali ke dalam toples dan diberi pakan mentimun.

Aplikasi formulasi kering berbahan aktif jamur M. anisopliae konsentrasi $20 \%$ dan B. bassiana konsentrasi $25 \%$ dilakukan dengan cara melarutkan formulasi kering dengan air. Setelah itu ditambahkan bahan perata perekat (indostick) sebanyak $1 \mathrm{ml} \mathrm{l}^{-1}$. Aplikasi ketiga jamur entomopatogen dilakukan pada sore hari dengan cara menyemprotkan cairan suspensi pada buah kakao yang telah di kurung dengan kain kasa dan berisi 10 ekor Helopeltis spp.

Pada percobaan di laboratorium dilakukan pengamatan pada mortalitas Helopeltis spp. yang terinfeksi ketiga jamur entomopatogen. Pengamatan dilakukan pada 10 hsa. Untuk memastikan kematian Helopeltis spp. akibat infeksi jamur M. anisopliae dan Beauveria bassiana maka disiapkan cawan petri untuk tiap perlakuan yang sudah diberi tisu dan dilembabkan dengan air, selanjutnya Helopeltis spp. yang mati diletakkan pada cawan tersebut. Apabila Helopeltis spp. mati akibat infeksi jamur $M$. anisopliae maka keesokannya akan didapati jamur berwarna hijau pada tubuh serangga dan apabila keesokannya serangga berwarna putih berarti terinfeksi jamur B. bassiana.

Pada percobaan di lapangan dilakukan pengamatan dengan melihat tingkat kerusakan yang diakibatkan oleh hama Helopeltis spp. pada buah kakao yang ditandai dari banyaknya tusukan pada buah kakao. Selain melihat tingkat kerusakan yang diakibatkan oleh hama Helopeltis spp. dilakukan juga pengamatan jumlah mortalitas Helopeltis spp. yang mati akibat infeksi jamur M. anisopliae dan Beauveria bassiana.

Tabel 1. Komposisi Formulasi Kering Jamur $M$. anisopliae \& B. Bassiana.

\begin{tabular}{clc}
\hline No & Bahan & Jumlah $(\mathrm{g})$ \\
\hline 1. & Tepung Biomassa Spora & 40 \\
2. & Kaolin & 20 \\
3. & Zeolit & 20 \\
4. & Tepung Jagung & 20 \\
\hline & Total & 100 \\
\hline
\end{tabular}


Apabila Helopeltis spp. mati akibat infeksi jamur $M$. anisopliae maka keesokannya akan didapati jamur berwarna hijau pada tubuh serangga dan apabila keesokannya serangga berwarna putih berarti terinfeksi jamur B. bassiana.

Mortalitas Helopeltis spp. yang diperoleh dari percobaan di laboratorium dianalisis dengan menggunakan uji Duncan dengan taraf nyata 5\%. Percobaan di lapangan dianalisis menggunakan analisis ragam dan dilanjutkan dengan Uji BNT dengan taraf nyata 5\% . Menurut Rustama et al. (2008) persentase mortalitas (kematian) serangga dapat dihitung menggunakan rumus seperti berikut:

$$
M=\frac{n}{N} \times 100 \%
$$

Keterangan :

$\mathrm{M}=$ Mortalitas serangga $(\%)$

$\mathrm{n}=$ Serangga yang mati (ekor)

$\mathrm{N}=$ Jumlah serangga yang diuji (ekor)

Menghitung banyaknya tusukan Helopeltis spp. pada buah kakao dapat dihitung dengan rumus seperti berikut:

$$
k=\frac{l}{m}
$$

Keterangan :

$\mathrm{k}=$ Jumlah tusukan perbuah

1 = Jumlah total tusukan per perlakuan

$\mathrm{m}=$ Banyaknya jumlah ulangan

\section{HASIL DAN PEMBAHASAN}

Hasil percobaan menunjukkan bahwa aplikasi berbagai umur formulasi kering jamur $M$. anisopliae isolat UGM dan Tegineneng serta $B$. bassiana isolat Tegineneng dapat menyebabkan mortalitas Helopeltis spp. Pada Tabel 2 terlihat bahwa kemampuan formulasi kering M. anisopliae isolat UGM dan Tegineneng serta $B$. bassiana isolat Tegineneng dalam menginfeksi Helopeltis spp. semakin rendah dengan semakin lamanya masa penyimpanan formulasi kering tersebut. Menurut Prayogo et al. (2005), keefektifan jamur entomopatogen dalam menginfeksi inang dapat dipengaruhi oleh kerapatan konidia, frekuensi aplikasi, umur inang, dan waktu penyimpanan jamur entomopatogen. Waktu penyimpanan bioinsektisida yang efektif untuk membunuh larva $S$. incertulas adalah 1 bulan. Dari penelitian sebelumnya oleh Julisetiyowatie (2011) umur biakan $M$. anisopliae sangat mempengaruhi virulensinya pada larva $S$. litura, biakan cendawan berumur 1 bulan paling efektif mengendalikan S. litura. Virulensi bioinsektisida yang disimpan lebih

Tabel 2. Mortalitas Helopeltis spp. setelah aplikasi formulasi kering jamur M. anisopliae isolat UGM dan Tegineneng serta $B$. bassiana isolat Tegineneng di laboratorium pada berbagai masa simpan.

\begin{tabular}{cccc}
\hline \multirow{2}{*}{$\begin{array}{c}\text { Masa simpan formulasi } \\
\text { kering (bulan) }\end{array}$} & \multicolumn{3}{c}{ Mortalitas Helopeltis spp. (\%) } \\
\cline { 2 - 4 } & $\begin{array}{c}\text { M. anisopliae isolat } \\
\text { UGM }\end{array}$ & $\begin{array}{c}\text { M. anisopliae } \\
\text { isolat Tegineneng }\end{array}$ & $\begin{array}{c}\text { B. bassiana } \\
\text { isolat Tegineneng }\end{array}$ \\
\hline 1 & $76,6 \mathrm{a}$ & $83,3 \mathrm{a}$ & $53,3 \mathrm{a}$ \\
2 & $61,6 \mathrm{~d}$ & $71,6 \mathrm{~b}$ & $51,6 \mathrm{a}$ \\
3 & $73,3 \mathrm{ab}$ & $66,6 \mathrm{c}$ & $55,0 \mathrm{a}$ \\
4 & $70,0 \mathrm{bc}$ & $63,3 \mathrm{c}$ & $55,0 \mathrm{a}$ \\
5 & $70,0 \mathrm{bc}$ & $63,3 \mathrm{c}$ & $55,0 \mathrm{a}$ \\
6 & $68,3 \mathrm{c}$ & $63,3 \mathrm{c}$ & $55,0 \mathrm{a}$ \\
7 & $60,0 \mathrm{de}$ & $55,0 \mathrm{~d}$ & $50,0 \mathrm{bc}$ \\
8 & $56,6 \mathrm{ef}$ & $55,0 \mathrm{~d}$ & $45,0 \mathrm{~cd}$ \\
9 & $55,0 \mathrm{fg}$ & $53,3 \mathrm{de}$ & $40,0 \mathrm{de}$ \\
10 & $53,3 \mathrm{fgh}$ & $50,0 \mathrm{ef}$ & $36,6 \mathrm{de}$ \\
11 & $51,6 \mathrm{gh}$ & $46,6 \mathrm{fg}$ & $31,6 \mathrm{e}$ \\
\hline
\end{tabular}

Keterangan : Angka-angka sekolom yang diikuti dengan huruf yang sama tidak berbeda nyata pada uji Duncan taraf nyata $5 \%$. 
Tabel 3. Persentase mortalitas dan rerata jumlah tusukan Helopeltis spp. setelah aplikasi jamur M. anisopliae isolat UGM dan Tegineneng serta B. bassiana isolat Tegineneng di lapangan.

\begin{tabular}{lcc}
\hline \multicolumn{1}{c}{ Perlakuan } & \% Mortalitas 10 hsa & Banyak tusukan per buah \\
\hline P0 (kontrol) & $20,0 \mathrm{~b}$ & $183 \mathrm{a}$ \\
P1 (M. anisopliae isolat UGM) & $83,3 \mathrm{a}$ & $120 \mathrm{~b}$ \\
P2 (M. anisopliae isolat Tegineneng) & $76,6 \mathrm{a}$ & $116 \mathrm{~b}$ \\
P3 (B. bassiana isolat Tegineneng) & $76,6 \mathrm{a}$ & $135 \mathrm{~b}$ \\
\hline BNT 0,05 & 8,3 & 25,7 \\
\hline
\end{tabular}

Keterangan : Angka-angka sekolom yang diikuti dengan huruf yang sama tidak berbeda nyata pada uji BNT taraf nyata $5 \%$.

dari 2 bulan akan menurun karena nutrisi dalam media banyak digunakan untuk memproduksi konidia sehingga cendawan kehabisan cadangan nutrisi. Pada bioinsektisida ini kerapatan konidia dan viabilitas konidia juga akan menurun.

Hasil percobaan di lapangan menunjukkan bahwa aplikasi formulasi kering jamur $M$. anisopliae isolat UGM dan Tegineneng serta B. bassiana isolat Tegineneng dapat menyebabkan mortalitas Helopeltis spp. Formulasi kering yang diaplikasikan di lapangan adalah formulasi yang baru dibuat dan belum mengalami masa penyimpanan. Hasil yang diperoleh menunjukkan bahwa mortalitas Helopeltis spp. cukup tinggi pasca aplikasi ketiga jenis jamur entomopatogen tersebut (Tabel 3). Pada Tabel tersebut dapat dilihat bahwa aplikasi formulasi kering $M$. anisopliae isolat UGM, Tegineneng serta $B$. bassiana di lapangan sangat efektif dalam mengendalikan hama Helopeltis spp. Hal ini sejalan dengan pernyataan Prayogo \& Tengkano (2002) bahwa tingkat mortalitas $M$. anisopliae terbaik terhadap $S$. litura sekitar mencapai $70 \%$ dan menurut Junianto \& Sulistyowati (2000) tingkat mortalitas paling rendah pada $B$. bassiana terhadap Helopeltis spp. sekitar 50\%. Hasil percobaan menunjukkan bahwa kemampuan menyerang Helopeltis spp. pada buah kakao yang telah diaplikasi formulasi kering jamur $M$. anisopliae isolat UGM dan Tegineneng serta $B$. bassiana isolat Tegineneng menurun dibandingkan dengan kontrol. Hal ini ditunjukkan dari banyaknya tusukan pada buah kakao setelah pengamatan 10 hsa (Tabel 3).

\section{KESIMPULAN}

Berdasarkan percobaan yang telah dilakukan dapat disimpulkan bahwa aplikasi formulasi kering jamur entomopatogen $M$. anisopliae isolat UGM dan
Tegineneng serta $B$. bassiana isolat Tegineneng pada masa simpan 1-6 bulan menyebabkan mortalitas Helopeltis spp. lebih tinggi dibandingkan dengan masa simpan 7-12 bulan di laboratorium. Formulasi kering jamur entomopatogen $M$. anisopliae isolat UGM dan Tegineneng serta $B$. bassiana isolat Tegineneng yang tidak mengalami masa simpan dapat menyebabkan mortalitas dan dapat mengurangi banyaknya tusukan Helopeltis spp. pada buah kakao di lapangan.

\section{DAFTAR PUSTAKA}

Balittri. 2012. Status komoditas kakao. http:// balittri.litbang.deptan.go.id/index.php/ komoditas/66-kakao/101-status-komoditasdan-daerah-pengembangannya. Diakses pada tanggal : 28 mei 2013.

Dwipayana G.A.O. 2013. Pengaruh aplikasi beberapa konsentrasi formulasi kering jamur Beauveria bassiana (Balsamo) Vuillemin isolat Tegineneng terhadap mortalitas hama pengisap buah kakao (Helopeltis spp.) di Laboratorium. (Skripsi). Universitas Lampung. Bandar Lampung.

Erdiyanto E. 2013. Pengaruh konsentrasi formulasi kering Metarhizium anisopliae isolat dari Yogyakarta terhadap mortalitas kepik penghisap buah kakao (Helopeltis spp.). (Skripsi). Universitas Lampung. Bandar Lampung.

Indriyati. 2009. Virulensi jamur entomopatogen Beauveria bassiana (Balsamo) Vuillemin terhadap kutu daun (Aphis spp.) dan kepik hijau (Nezara viridula). J. HPT Tropika 9(2): 92-98. 
Julisetyowatie A. 2011. Efikasi jamur entomopatogen (Metarhizium anisopliae, Beauveria bassiana) dan bakteri entomopatogen (Bassillus thuringiensis) sebagai pengendali Spodoptera litura (Lepidoptera: Noctuidae). (Tesis). Program Pasca Sarjana Universitas Sriwijaya. Palembang.

Junianto D. dan Sulistyowati E. 2000. Produksi dan aplikasi Beauveria bassiana untuk pengendalian penghisap buah kakao (Helopeltis spp.) dan penggerek buah kakao (Conomorpha cramerella). Simposium Kakao. Pusat Penelitian Kopi dan Kakao Jember. Jakarta, 1213 Juli 2002. 17p.

Mulya, K., S. Rusli, Supriyadi, E. A. Wikardi, M. Djazuli, E. Karmawati, D. Manohara, dan O. Rostiana (Ed.). 2002. Prosiding Seminar Nasional dan Pameran Pertanian Organik. Jakarta, 2-3 Juli.

Prayogo Y., Tengkano W., dan Marwanto. 2005. Prospek cendawan entomopatogen Metarhizium anisopliae untuk mengendalikan ulat grayak Spodoptera litura pada kedelai. J. Litbang Pertanian. 24(1): 19-26.

Prayogo Y. dan Suharsono. 2005. Optimalisasi pengendalian hama penghisap polong kedelai (Riptortus linnearis) dengan cendawan entomopatogen Verticillium lecanii. J. Litbang Pertanian. 24(4): 123-130.

Prayogo Y. 2006. Sebaran dan efikasi berbagai genus cendawan entomopatogen terhadap Riptortus linearis pada kedelai di Lampung dan Sumatra Selatan. J. HPT Tropika. 6(1): 14-22.
Purnomo, T.N. Aeny, dan Fitriana Y. 2012. Pembuatan dan aplikasi formulasi kering tiga jenis agensia hayati untuk mengendalikan hama pencucuk buah dan penyakit busuk buah kakao. Laporan Penelitian Hibah Bersaing. Universitas Lampung. Bandar Lampung.

Rahayu A. K. 2011. Keberadaan Helopeltis antonii sebagai hama pada beberapa tanaman perkebunan dan pengendaliannya. Balai Besar Perbenihan dan Proteksi Tanaman Perkebunan Surabaya.

Rustama M. M., Melanie, dan Irawan B. 2008. Patogenisitas jamur entomopatogen Metarhizium anisopliae terhadap Crocidolomia pavonana dalam kegiatan studi pengendalian hama terpadu tanaman kubis dengan menggunakan agensia hayati. Laporan penelitian. Universitas Padjadjaran. Jawa Barat. Diakses pada tanggal : 13 April 2013.

Saputra Z. 2013. Pengaruh aplikasi beberapa konsentrasi formulasi kering Metarhizium anisopliae isolat Tegineneng terhadap mortalitas hama pengisap buah kakao (Helopeltis spp.). (Skripsi). Universitas Lampung. Bandar Lampung.

Suparno T. 2000. Infestasi penggerek buah kakao kedalam Perkebunan Kakao di Kawasan Kerkap, Bengkulu Utara dan pengendaliannya. J. HPT Tropika. 1(1): 11-15.

Susilo, F. X. 2007. Pengendalian Hayati dengan Memberdayakan Musuh Alami Hama Tanaman. Graha Ilmu. Yogyakarta. $120 \mathrm{hlm}$. 